\title{
From Offline to Online: A Study on the Practice of Learners' Self-Regulated Learning Based on Bourdieu's Theory
}

\author{
Huifen Wang ${ }^{1}$ Chuan $\mathrm{Hu}^{1 *} \quad$ Shuya $\mathrm{Cai}^{2}$ \\ School of Management, Jinan University, 601 Huangpu Avenue West, Guangzhou 510632, China
}

\begin{abstract}
The research is financed by Reform of the Practical Teaching Mode of Enterprise Resource Planning Based on the Cultivation of Students' Learning Ability(55611219)
\end{abstract}

Abstract

At present, the migration of learners from offline classroom to online learning space faces the problem of high dropout rate. Previous research suggested that self-regulated learning practice is a key factor affecting the effectiveness of online learning, but the research on the driving causes of self-regulated learning is still in the exploration stage. In the study, the impact on self-regulated learning practice is investigated. Based on the practice theory of Bourdieu, a large number of interviews was conducted by the grounded theory methodology. The results indicated that the impact on learners' self-regulated learning practice was accomplished by four aspects, i.e., online field structured, capitals reproduced, new habitus generated and practice of self-regulated learning. The managerial implications from our study are discussed finally.

Keywords: Bourdieu theory; self-regulated learning; practice

DOI: $10.7176 / \mathrm{EJBM} / 11-32-01$

Publication date: November $30^{\text {th }} 2019$

\section{Introduction}

The development of the internet has prompted online courses to be popular and many people have migrated to online to learn. Online learning is conducted in an open virtual cyberspace, including teacher customized teaching, anonymous interaction between teachers and students, and online innovative course assessment and so on. Unlike traditional learning where students learn synchronously, students who study online have more opportunities and access to obtain additional resources(Artino\&Jones,2012;Schrum,2000). As one of the representative products of technical practice in education, MOOC has accelerated the pace of individualized independent learning development with advanced digital means and diverse digital resources. However, the dropout rate in MOOC is very high. Statistics show that only about $8.56 \%$ of MOOC learners have completed the course study(Lin Jiang et al.,2013). Success in an online learning environment depends on a students' ability to engage in the learning process actively and autonomously(Wang,Shannon\&Ross,2013). Wu proposed that the failure of the online class is that the accessibility of knowledge is higher than the learners' adaptability. With the evolution of Web2.0 and Web3.0 technologies, the learning behavior of a new generation of learners presents differently, and it is a need to summarize the characteristics of such learning activities and understand what factors driving learners to engage.

Knowles(1975) defined self-regulated learning as a series of learning processes in which learners voluntarily clarify their own learning needs to develop learning objectives, find learning resources, practice learning strategies, and evaluate learning outcomes. Previous research has demonstrated that online selfregulated learning has a positive impact on learning outcomes(Bernacki et al.,2011).Hood et al.(2015)reported that self-regulated learning plays in supporting role in online learning. The further research verified that knowledge context and current role can influence the formation of learners' self-regulated learning characteristics(Hood et al.,2015). Broadbent et al. (2015)have fond that time management, metacognition, effort regulation, and critical thinking were positively correlated with academic outcomes.

The current research preliminarily focus on the influencing results of the learners' self-regulated learning practice, but the movement toward online learning is not grounded in empirical evidence that what is beneficial for self-regulated learning(Hannafin et al.,2003). Yet the generative mechanism of learners' self-regulated learning practice is still unclear. It advocates further research could develop a new theoretical perspective to deeply explore the nature of digital education. To answer the question of how learners' self-regulated learning practice converted from offline to online, The purpose of this paper is to introduces the practice theory of Bourdieu for interpreting the influencing factors of learners' self-regulated learning practice online. There are two key contributions: (1) The research based on the practice theory of Bourdieu which provide a new perspective on online learning research. (2) A large number of interviews provide strong references for bestpractices on online learning development.

\section{Theoretical background}

Bourdieu's practical theory consists of three parts: field, capital (economic capital, cultural capital, social capital and symbolic capital) and habitus, they are key factors in social practice. Bourdieu further summarized their 
relationship:

$$
\text { Practice }=(\text { habitus } * \text { capital })+\text { field }
$$

Habitus is the embodiment of agents 's history, which can shape the way individuals exist and act in the social world. As a kind of temperament tendency system, habitus condenses the practical experience of agents, meanwhile, actively externalizes and generates its own action strategy (Fayard \& Weeks, 2014). Habitus are different from "habits", both of them have empirical factors acquired in daily behavioral activities, but habits tend to emphasize spontaneous, repetitive, and mechanical experience, while habitus represents regenerative, creative, and constructive experience(Xuanyang Gao,2008). Habitus can be displayed with uncertain features, and can be accurately grasped under empirical methods.

The field defined as the social space practiced by agents. It is a structured structure of the social network and social status of the individual. The world is made up of many fields, and each field has its own unique practice logic. In the Bourdieu's theory, the field provides struggle space for agents who use their capitals. There are four types of capital: economic capital, cultural capital, social capital and symbolic capital. Economic capital is the most basic capital that refers to material wealth and resources. Cultural capital includes knowledge, skills, lifestyle, qualifications, etc. There are three forms of cultural capital: physical (taste and lifestyle, for example),objectified (cultural goods own by an agent) and institutionalized(for instance, educational qualifications)(Husu, 2012). Social capital depends on the size and number of social networks in the field, and network members can benefit from network links. Symbolic capital is the accumulation of reputation, privilege, etc. based on the logic of knowledge and recognition practice. Symbolic capital can be legalized if it is recognized(Conway et al.,2016).

Bourdieu's theory of practice is not only a description of the behavior itself or a practical tool, but a recognition of the meaning of structured activities behind the behavior. Bourdieu conceptualizes digital technology as a social tool, including the background, use, and nature of artifacts, which will help to understand the interrelationship between technology and practice, technology and individuals, and individuals and the environment(Beckman et al.,2018). He envisioned that the technical practice includes not only the use of technology, but also the society and culture, and system structure relationship in the process of using technology(Schreiber et al.,2013).

The online learning field has a relatively independent social relationship space and has its own practice logic. The technical practice of education promotes the learning habitus and capital changes of users' autonomy from time and space, and the socialized practice is shifted to the core level of technical practice.

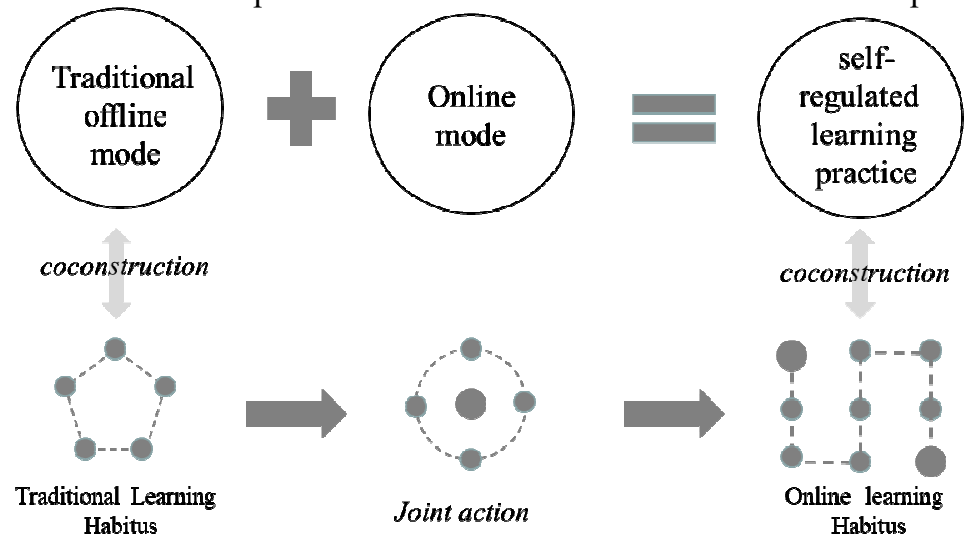

Figure 1. Diagrammatic representation of online learning practical logic

\section{The influencing factors of self-regulated learning practice}

\subsection{Methodology and Data Collection}

Grounded Theory is a qualitative study that answers the question of "why" and "what is". This method is widely used in exploratory research , and emphasize the bottom-up refining theory(Glaser et al.,1968). The grounded theory can not only enable us to see the localization characteristics of the educational phenomenon, but also provide new solutions to the current situation of practice (Martin \& Turner, 1986).Bourdieu's theory of practice focuses on how practice occurs and in what way it is developed, which has a certain fit with the method of grounded theory. For data collection, because this study mainly explores the influencing factors of online learners' self-learning practice, We make MOOC as the research object as it develops steadily and owns online learners of a certain size ,We selected 30 interviewees who have learning experience in MOOC and collected qualitative data through in-depth interviews, each interview lasted approximately 40 minutes, The details of the qualitative data are summarized in Table 1. 
Table 1. Details of the qualitative data

\begin{tabular}{|c|c|c|c|}
\hline basic information & characteristic & number & proportion \\
\hline \multirow{2}{*}{ gender } & male & 13 & $43.3 \%$ \\
\cline { 2 - 4 } & female & 17 & $56.7 \%$ \\
\hline \multirow{3}{*}{ age } & $18-22$ & 9 & $30 \%$ \\
\cline { 2 - 4 } & $22-25$ & 14 & $46.7 \%$ \\
\cline { 2 - 4 } & $26-30$ & 7 & $23.3 \%$ \\
\hline \multirow{3}{*}{ learning time } & 0.5 year-1 year & 14 & $46.7 \%$ \\
\cline { 2 - 4 } & 1 year-3 years & 5 & $16.7 \%$ \\
\cline { 2 - 4 } & more than 3years & 11 & $36.6 \%$ \\
\hline
\end{tabular}

\subsection{Data Analysis and Results}

Based on the preliminary analysis of the data collected by the interviews, this study conceptualized the phenomena emerging from the original data while a large number of possible categories are identified. through continuous analysis, comparison and classification to find out the potential context, We form the main category (Juliet M. Corbin \&Anselm L.Strauss,2015). According to the data analysis, we propose six main categories and eleven sub-categories, the partial details are summarized in table 2.

Table 2. Categories from the data analysis

\begin{tabular}{|c|c|c|}
\hline $\begin{array}{c}\text { Main } \\
\text { categories }\end{array}$ & $\begin{array}{c}\text { Sub- } \\
\text { categories }\end{array}$ & Data of interviews \\
\hline $\begin{array}{c}\text { teachers' } \\
\text { cultural } \\
\text { capital }\end{array}$ & profession & $\begin{array}{l}\text {-The class quality in MOOC is excellent } \\
\text { - The class design in MOOC is attractive and interesting }\end{array}$ \\
\hline \multirow{2}{*}{$\begin{array}{l}\text { teachers' } \\
\text { symbolic } \\
\text { capital }\end{array}$} & $\begin{array}{l}\text { identity } \\
\text { recognition }\end{array}$ & $\begin{array}{l}\text { - The quality courses are generally taught by famous teachers } \\
\text { - Some famous teachers have personally produced courses. the knowledge } \\
\text { application could be better }\end{array}$ \\
\hline & $\begin{array}{l}\text { social } \\
\text { status }\end{array}$ & $\begin{array}{l}\text { - teachers generally have a high reputation in society } \\
\text { - I choose many outstanding and well-known teachers to follow }\end{array}$ \\
\hline \multirow{2}{*}{$\begin{array}{l}\text { learners' } \\
\text { cultural } \\
\text { capital }\end{array}$} & $\begin{array}{l}\text { knowledge } \\
\text { base }\end{array}$ & $\begin{array}{l}\text { - I usually find the content of the knowledge structure related to my own learning, } \\
\text { and then expand it on the platform } \\
\text { - I learned online because I have not learned too well before }\end{array}$ \\
\hline & $\begin{array}{l}\text { information } \\
\text { literacy }\end{array}$ & $\begin{array}{l}\text { - I always browse experience stickers and search directly for the course I want to } \\
\text { know } \\
\text { - I always look at the number of people online and try it out in a few classes, then } \\
\text { pick the class that I like }\end{array}$ \\
\hline $\begin{array}{l}\text { learners' } \\
\text { economic } \\
\text { capital }\end{array}$ & $\begin{array}{l}\text { knowledge } \\
\text { investment }\end{array}$ & $\begin{array}{l}\text { - I have the money and insist on learning when I have the learning resources I } \\
\text { really want on the platform } \\
\text { - After purchasing a course online, I feel that the course quality is high and } \\
\text { resources are scarce }\end{array}$ \\
\hline \multirow{2}{*}{$\begin{array}{l}\text { learners' } \\
\text { social capital }\end{array}$} & $\begin{array}{l}\text { interaction } \\
\text { (Breath) }\end{array}$ & $\begin{array}{l}\text { - I talked with online friends about how to find online courses and they } \\
\text { recommended many learning platform for me } \\
\text { - I can meet many new friends on the platform who usually share the course } \\
\text { experience and recommend some courses }\end{array}$ \\
\hline & $\begin{array}{l}\text { interaction } \\
\text { (Depth) }\end{array}$ & $\begin{array}{l}\text { - The forum allows a lot of students to speak freely and deeply } \\
\text { - In the traditional class, I only discuss problems with my classmates, and the } \\
\text { results and process of discussion are not as diverse as those of the online class }\end{array}$ \\
\hline \multirow[b]{2}{*}{ online field } & $\begin{array}{l}\text { learning } \\
\text { rules }\end{array}$ & $\begin{array}{l}\text { - The course I choose can be studied anytime, anywhere } \\
\text { - There are clear terms and forms for submitting assignments }\end{array}$ \\
\hline & $\begin{array}{l}\text { learning } \\
\text { atmosphere }\end{array}$ & $\begin{array}{l}\text { - I have participated in the self-study room punching and rewarding activities, and } \\
\text { the learners who punch the cards every day have the opportunity to draw prizes } \\
\text { - A learning group can be set up on the platform to supervise my learning every } \\
\text { day }\end{array}$ \\
\hline \multirow[t]{2}{*}{$\begin{array}{l}\text { Online } \\
\text { habitus }\end{array}$} & $\begin{array}{c}\text { sense of } \\
\text { subjectivity }\end{array}$ & $\begin{array}{l}\text { - The course can be chosen by myself. If I don't like the teacher's course, I can } \\
\text { change the course without feeling bound } \\
\text { - I will feel that learning is my own thing, not mandatory by the teacher, and I can } \\
\text { better plan my own learning progress. }\end{array}$ \\
\hline & $\begin{array}{l}\text { sense of } \\
\text { efficacy }\end{array}$ & $\begin{array}{l}\text { - successful learning by myself brings me more confidence } \\
\text { - I can achieve my learning expectations through my efforts }\end{array}$ \\
\hline
\end{tabular}


Selective coding comes after open coding and spindle coding. Selective coding is the deep mining of the relationship between the main category and the sub-category obtained in the first two coding stage, revealing the typical relationship structure between the categories, so that the theoretical framework can be presented in the form of a complete story line. The story line is as followed:

Driving the self-regulated learning practice usually comes from two aspects, the online social space represented by the field and the individual with capitals. When the online learning field and the learner's habitus meet, the learner will strategically mobilize or fight for the capital which is conducive to the decision of his own behavior, thus realizing the reshaping of habitus and guiding self-regulated learning practice.

Referencing some literatures and reanalyzing the interviews' content, we propose a map to describe the influencing factors of the learners' self-regulated learning practice which is depicted in Fig.2. online field structured, capitals reproduced, new habitus generated are which make the practice of self-regulated learning.

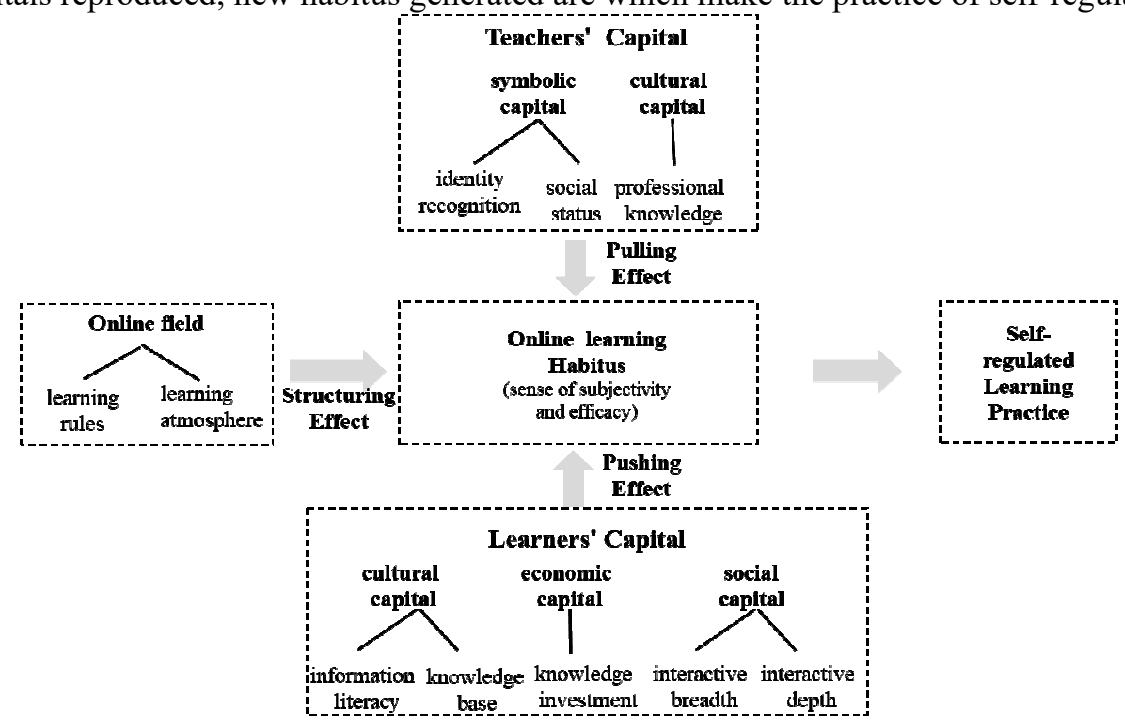

Figure 2. The path of the self-regulated learning practice generated online

Online field has a structuring effect on new learning habitus. The traditional learning field has unified learning rules. For teachers, there are established teaching objectives of talent training and specific teaching steps. For learners, there are clear selection requirements, assessment indicators and assessment methods. There is no unified learning rules in online field, such as the blurred boundaries of teachers and students and no boundaries in learning time and space. The content and the learning process of the courses in the field are diversified .When learners enter the online learning field. they only need to learn from preferred teachers and courses to suit individual needs. From the interview, we found that some learners feel that an unsupervised learning environment can be uncomfortable at first, but they can design a virtual position for learning through the selfregulated planning and enter into the state of autonomous learning without interference from the external things. Therefore, learners can express self-regulated behaviors when their own habitus adjusted to the online field, and they structure the new habitus in the continuous practice.

Capital is seen as a practice tool, and different fields have different capital forces. The education field mainly focuses on the accumulation of cultural capital. Other types of capital (economic capital, social capital, symbolic capital) play supporting roles. From the interview, we found that the main capital forms of the online learning field are learners' economic capital, social capital and cultural capital, meanwhile teachers' cultural capital and symbolic capital have a promoting effect.

Economic capital refers to the intangible or tangible material resources that an individual can coordinate. In the online field, we found that the low threshold of the online learning platform confused learners to choose the course that suits them. Knowledge payment is undoubtedly a filter for quality resources. Some interviewees say that they are glad to invest more time and energy to adapt to the pace of online learning when the learning is based on a certain economic basis. Social capital is a kind of the potential resources that can be accessed through a durable network of relationships (Pret et al., 2016). Clercq(2012) pointed out that social interaction density stands for the amount of individual social resources. Learners access heterogeneous resources through participating in online interactive channels such as course comment areas, knowledge forums, and study groups. Based on the establishment of the strangers' social network, interviewees agree that the individual has a more open and active social network management ability, which has an important influence on their self-regulated learning practice. Different practices will result in inequality of the initial cultural capital of the educated, thus affecting the cultural capital reproduction. The accumulation and pursuit of physical cultural capital is the main underlying factor to express different learning practice, moreover, information literacy is a kind of 
distinguishable culture capital . During the process of collating the interview data, we found that "searching for keyword keywords", "seeing the number of comments", and "seeing the schedule in advance" appeared many times, indicating that information literacy plays an important role in the learning process.

The external factors that promote learners' online learning are the cultural capital and the symbolic capital of teachers. These teachers come from famous universities and own the title and recognition of professional fields. During the interview, some interviewees also said: "There are some better teachers on the platform and have increased their interest in the course". Symbolic capital is a legalized cultural capital that assumes the function of most cultural capital (Pret et al., 2016). Bourdieu believes that symbolic capital has three functions: cognitive function, communication function and social differentiation function. For learners, the symbolic capital of teachers enables them to practice based on the mainstream culture, and they subconsciously expect to reach a spiritual resonance with famous teachers.

Habitus conversion is an interactive process in the new field, and capital plays an important role. In Vonderwell's(2003) study, he reported that lack of a sense of community was a challenge for online learning, especially "one-on-one" relationship with the instructor. It means that learners faces the situation that the existing habitus does not match the new field. Through the interaction of the online field and different capitals, the learners struggled from the traditional knowledge authority, gradually changed the habitus of passive learning in the past, and produced the sense of subjectivity and efficacy, thus formed a new habitus of selfregulated learning. In short, The practice theory of Bourdieu helps to explain the influencing factors of selfregulated learning practice with the role of capital, habitus and field.

\section{Conclusion}

The emergence of online learning platforms such as MOOCs has inspired learners to move from offline learning field to online learning field, but the habitus of learners in specific fields are not applicable to another field. Therefore, field change reflects the adaptive process of the learner's habitus transformation. Based on the practice theory of Bourdieu and the grounded theory methodology, the present study reveals that online selfregulated learning practice is a process in which old habitus transformed into new habitus, and is mainly influenced by the learners' capital and teachers' capital and the structural influence of the online field.

The conclusions of this study help the platform managers and learners to understand the generation of learning practices and develop strategies to maintain learners' continuous engagement in online learning. The managerial implications obtained by the study is twofold: For platform managers, it is necessary to further improve the community construction of the online field. on the one hand, depicting the learner's portrait to innovate learning rules and learning methods, for example, creating the gamification incentive mechanism, such as establish the learning punch card point system to encourage them improve their levels based on the learning time and grant corresponding honorary status to improve the learner's self-identity. on the other hand, introducing live streaming teaching to strengthen teacher-student capital interaction to maintain learners to participate in online learning. For learners, they must own a sense of active presence and enable to mobilize different internal and external resources, thus adapting their habitus to the new learning field to achieving their learning goals.

\section{References}

Artino, A.R., \& Jones, K. (2012). Exploring the complex relations between achievement emotions and selfregulated learning behaviors in online learning. The Internet and Higher Education, 15(3), 170-175.

Schrum, L.M. (2000). Guarding the promise of online learning. Education Digest, 66(4), 43-47.

Lin Jiang, Xibin Han, \& Jiangang Cheng. (2013). Research on MOOCs learner characteristics and learning effects. China Educational Technology (11), 54-59.

Wang, C.H., Shannon, D., \& Ross,M. (2013). Students' characteristics, self-regulated learning, technology selfefficacy, and course outcomes in online learning. Distance Education, 34(3), 302-323.

Nanzhong Wu. (2016). On the Changes of Online Learning Paradigm: From Autonomous Learning to Adaptive Learning. Modern Distance Education(2), 42-48.

Knowles M S. (1975).Self-Directed Learning: A Guide for Learners and Teachers. Journal of Continuing Education in Nursing, 7(3),60.

Bernacki, M., Aguilar, A., \& Byrnes, J. (2011). Self-regulated learning and technology enhanced learning environments: An opportunity propensity analysis. In G. Dettori,\& D. Persico (Eds.), Fostering selfregulated learning through ICT (pp. 1-26). Hershey,PA: IGI Global Publishers.

Hood, N., Littlejohn, A., \& Milligan, C. (2015). Context counts: How learners' contexts

influence learning in a MOOC. Computers \& Education, 91, 83-91.

J. Broadbent, W.L. Poon. (2015) .Self-regulated learning strategies \& academic achievement in online higher education learning environments: A systematic review. The Internet and Higher Education(27),1-13

Hannafin, M.J., Hill, J.R., Oliver, K., Glazer, E., \& Sharma, P. (2003). Cognitive and learning factors in Web- 
based distance learning environments. In M.G. Moore, \& W.G. Anderson (Eds.), Handbook of distance education ( pp. 245-260). Mahwah,NJ: Erlbaum

Bourdieu P. (1985). Distinction. a social critique of the judgement of taste. Oxford Art Journal, 8(2), 63-67.

Fayard, A.L.,\&Weeks,J..(2014). Affordances for practice. Information and Organization, 24(4), 236-249.

Xuanyang Gao.(2008).On Bourdieu's "Habitus". Journal of Yunnan University(Social Sciences Edition) ,7(3): 815

Husu, H. M. (2012). Bourdieu and social movements: considering identity movements in terms of field, capital and habitus. Social Movement Studies, 12(3), 1-16.

Conway, S. F. , Mcdonagh, J. , Farrell, M. , \& Kinsella, A. (2016). Cease agricultural activity forever? underestimating the importance of symbolic capital. Journal of Rural Studies, 44, 164-176.

Beckman, Karley, Apps, Tiffani, Bennett, Sue, \& Lockyer.(2018). Conceptualising technology practice in education using Bourdieu's sociology. Learning, Media and Technology(1), 1-14.

Schreiber D.(2013). Book review: Practice theory, work, and organization: An introduction Management Learning, 44(5),556-557.

Glaser, B., \& Strauss, A. L. (1968). The discovery of grounded theory: strategies for qualitative research. Nursing Research, 17(4), 377-380.

Bourdieu, P. (1990). In other words : essays towards a reflexive sociology. Cambridge: Polity Press

Martin, \& P., Y. (1986). Grounded theory and organizational research. The Journal of Applied Behavioral Science, 22(2), 141-157.

Juliette M. Corbin, \& Anselm L. Strauss. (2015). Foundations of qualitative research. Chongqing University Press.

PRET, T., SHAW, E. \& DRAKOPOULOU DODD, S. (2016), Painting the full picture: The conversion of economic, cultural, social and symbolic capital, International Small Business Journal, 34( 8), 1004-1027.

Clercq, B. D. , Vyncke, V. , Hublet, A. , Elgar, F. J. , Ravens-Sieberer, U. , \& Currie, C. , et al. (2012). Social capital and social inequality in adolescents' health in 601 flemish communities: a multilevel analysis. Social Science \& Medicine, 74(2), 202-210.

Bourdieu P. (1991).Language and symbolic power. Harvard University Press

Vonderwell, S. (2003). An examination of asynchronous communication experiences and perspectives of students in an online course: A case study. Internet and Higher Education, 6, 77-90. 